\title{
Exploring the impact of a decision support algorithm to improve clinicians' chemotherapy-induced peripheral neuropathy assessment and management practices: a two-phase, longitudinal study
}

Robert Knoerl ${ }^{1 *}$ (D) Emanuele Mazzola ${ }^{2}$, Fangxin Hong ${ }^{2}$, Elahe Salehi ${ }^{3}$, Nadine McCleary ${ }^{3}$, Jennifer Ligibel ${ }^{3}$, Kaitlen Reyes ${ }^{3}$ and Donna L. Berry ${ }^{4}$

\begin{abstract}
Background: Chemotherapy-induced peripheral neuropathy (CIPN) negatively affects physical function and chemotherapy dosing, yet, clinicians infrequently document CIPN assessment and/or adhere to evidence-based CIPN management in practice. The primary aims of this two-phase, pre-posttest study were to explore the impact of a CIPN clinician decision support algorithm on clinicians' frequency of CIPN assessment documentation and adherence to evidence-based management.
\end{abstract}

Methods: One hundred sixty-two patients receiving neurotoxic chemotherapy (e.g., taxanes, platinums, or bortezomib) answered patient-reported outcome measures on CIPN severity and interference prior to three clinic visits at breast, gastrointestinal, or multiple myeloma outpatient clinics ( $n=81$ usual care phase [UCP], $n=81$ algorithm phase [AP]). During the AP, study staff delivered a copy of the CIPN assessment and management algorithm to clinicians $(N=53)$ prior to each clinic visit. Changes in clinicians' CIPN assessment documentation (i.e., index of numbness, tingling, and/ or CIPN pain documentation) and adherence to evidence-based management at the third clinic visit were compared between the AP and UCP using Pearson's chi-squared test.

Results: Clinicians' frequency of adherence to evidence-based CIPN management was higher in the AP (29/52 [56\%]) than the UCP (20/46 [43\%]), but the change was not statistically significant $(p=0.31)$. There were no improvements in clinicians' CIPN assessment frequency during the AP (assessment index $=0.5440$ ) in comparison to during the UCP (assessment index $=0.6468$ ).

Conclusions: Implementation of a clinician-decision support algorithm did not significantly improve clinicians' CIPN assessment documentation or adherence to evidence-based management. Further research is needed to develop theory-based implementation interventions to bolster the frequency of CIPN assessment and use of evidence-based management strategies in practice.

(Continued on next page)

\footnotetext{
* Correspondence: robert_knoerl@dfci.harvard.edu

${ }^{1}$ Dana-Farber Cancer Institute, Boston, MA, USA

Full list of author information is available at the end of the article
}

(c) The Author(s). 2021 Open Access This article is licensed under a Creative Commons Attribution 4.0 International License, which permits use, sharing, adaptation, distribution and reproduction in any medium or format, as long as you give appropriate credit to the original author(s) and the source, provide a link to the Creative Commons licence, and indicate if changes were made. The images or other third party material in this article are included in the article's Creative Commons licence, unless indicated otherwise in a credit line to the material. If material is not included in the article's Creative Commons licence and your intended use is not permitted by statutory regulation or exceeds the permitted use, you will need to obtain permission directly from the copyright holder. To view a copy of this licence, visit http://creativecommons.org/licenses/by/4.0/ The Creative Commons Public Domain Dedication waiver (http://creativecommons.org/publicdomain/zero/1.0/) applies to the data made available in this article, unless otherwise stated in a credit line to the data. 
(Continued from previous page)

Trial registration: ClinicalTrials.Gov, NCT03514680. Registered 21 April 2018.

Keywords: Peripheral nervous system diseases, Neoplasms, Algorithms, Decision Support systems, Clinical, Documentation, Chemotherapy-induced peripheral neuropathy

\section{Introduction}

Chemotherapy-induced peripheral neuropathy (CIPN) is a frequent dose-limiting complication of neurotoxic chemotherapy (e.g., taxanes, oxaliplatin, bortezomib) [1, 2 ] associated with numbness, tingling, and pain in the hands or feet [2]. For example, taxane-induced peripheral neuropathy symptoms (e.g., numbness or tingling) generally present in a stocking-glove distribution [3], acute oxaliplatin-induced peripheral neuropathy symptoms are characterized by brief cold-induced neuropathic pain and muscle cramps [4], while bortezomibinduced peripheral neuropathy often presents with pain [5]. The symptoms of CIPN are difficult to assess and manage because patients have difficulty describing the sensations they are experiencing [6] and there are few treatment options [7]. Subsequently, poorly managed CIPN may impair physical function $[8,9]$ and increase health care utilization and expenditures [10].

To prevent the untoward effects of CIPN, clinicians should assess patients for CIPN regularly during neurotoxic chemotherapy to identify risk and manage early CIPN symptoms. However, qualitative and quantitative evidence suggests that CIPN is under assessed and managed by clinicians. Participants in qualitative studies have reported that clinicians do not adequately follow up on CIPN concerns or provide much feedback about how to manage CIPN $[6,11]$. A medical record review of breast clinician' notes by Knoerl et al. (2018) revealed that CIPN-related numbness or tingling was documented in approximately $28 / 48$ notes (58.3\%) [12]. Further, Knoerl et al. (2019) demonstrated that CIPN was discussed or documented in $44 \%$ and $46 \%$ of 159 audio recorded patient-clinician outpatient encounters and associated medical record notes (e.g., patients with breast, colorectal, prostate, and/or head and neck cancers), respectively [13]. In both studies, the first-line treatment recommended for painful CIPN (i.e., duloxetine) [7] was never prescribed to participants reporting CIPN $[12,13]$.

Previous research has demonstrated that the delivery of a web-based platform designed to capture CIPN patientreported outcomes at the point of care and provide clinicians and patients with generated treatment and/or self-care information: 1) is feasible to implement in an outpatient oncology clinic [14], 2) improves clinician documentation of nonpainful CIPN symptoms (i.e., numbness) [12], and 3) improves patients' activation in their care [15]. However, the previously tested web-based platform was delivered in one breast oncology clinic setting and in a relatively small number of patients ( $N=25$ Phase I, and $N=75$ Phase II) and clinicians $(N=6)$ [12]. To build upon this research, we revised the Algorithm for Nursing Assessment and Management of CIPN, an algorithm developed to guide nurses' decision making in the assessment and management of CIPN in clinical practice [16]. The revised algorithm incorporates data from the administration of standardized patient reported outcome measures and objective assessments (e.g., reflex and vibration testing) to generate evidence-based CIPN management recommendations for clinicians based on the patients' CIPN symptom presentation. Availability of the CIPN algorithm was hypothesized to influence clinicians' CIPN assessment and management behaviors because the algorithm provided clinicians with CIPN assessment and evidencebased management strategies and CIPN patient-reported outcome scores for use during the clinical encounter.

\section{Purpose}

The primary aims of this two-phase, pre-post longitudinal study were to explore the impact of a CIPN clinician decision support algorithm on clinicians' CIPN assessment documentation and adherence to evidencebased management in comparison to usual care. Secondarily, we assessed changes in patients' self-reported CIPN severity, worst pain intensity, and CIPN-related functional impairment between phases. Also, we determined the feasibility of algorithm delivery and clinicians' ratings of acceptability and satisfaction with the algorithm.

\section{Methods \\ Design, sample, setting}

The study aims were conducted using a two-phase, pre and post-test design. One-hundred sixty-two patients ( $n=81$ for usual care phase [UCP] and $n=81$ for algorithm phase $[\mathrm{AP}]$ ) and 53 clinicians were recruited. Patients were eligible if they were 1$) \geq 18$ years old, 2) finished at least one infusion of neurotoxic chemotherapy (e.g., taxanes, platinums, or bortezomib) for the treatment of breast, gastrointestinal or multiple myeloma malignancies, 3) scheduled to attend at least three more clinic visits associated with neurotoxic chemotherapy receipt after consent, 4) ambulatory, 5) proficient in English, and 6) receiving care from a clinician enrolled in the study. Patients were excluded if they had a prognosis of less than 2 months or documented peripheral neuropathy due to other causes (e.g., diabetes) $[17,18]$ 
prior to starting neurotoxic chemotherapy. Of note, the patient eligibility criteria were amended during the trial to enhance recruitment feasibility. At the onset of the trial, patients were eligible if they had received $\leq 1 / 3$ of the total planned neurotoxic chemotherapy regimen at the time of consent, planned to receive neurotoxic chemotherapy for $\geq 3$ months, and all three study visits could be completed within 12 weeks after consent. Clinicians were eligible if they were a medical doctor, nurse practitioner, or physician assistant providing care to patients at the breast, gastrointestinal, or multiple myeloma clinics at Dana-Farber Cancer Institute. Informed consent was obtained from all patient and clinician participants and study oversight and ethics approval was provided by the Dana-Farber/Harvard Cancer Center Office for Human Research Studies (18-049). Patients consented to either phase received a \$30 Amazon gift card at the conclusion of the study.

\section{Measures}

\section{Feasibility, acceptability, and satisfaction}

Feasibility of CIPN algorithm implementation was evaluated based on the number of times the clinicians received the CIPN algorithm prior to a clinic visit. In addition, a two-item feasibility questionnaire prompted clinicians to state how often they used the algorithm and other CIPN educational resources to guide the assessment and management of CIPN, respectively (each item scored from 1 to $5 ; 1=$ "never," $5=$ 'always'). Clinicians' perspectives of acceptability and satisfaction with the CIPN algorithm were evaluated using an adapted subset of eight questions from the Adapted Acceptability E - Scale [19]. Questions pertained to clinicians' ratings of satisfaction with algorithm use and how helpful the algorithm was in guiding patient interactions, promoting communication, and identifying areas of need (each item scored from 1 to 5; higher scores $=$ greater acceptability and satisfaction). Only clinicians who received the algorithm during the AP were invited to complete the Feasibility Questionnaire and Adapted Acceptability E - Scale.

\section{CIPN patient-reported outcomes}

The Patient Reported Outcomes version of the Common Terminology Criteria for Adverse Events (PRO-CTCA $\left.E^{\mathrm{st}}\right)$ Numbness and Tingling Severity and Interference Items ask patients to self-report the severity of numbness and tingling in the hands or feet ("none [0]," "mild [1]," "moderate [2]," "severe [3]," or "very severe [4]") at its worst in the past 7 days, and how much these symptoms have interfered with activities of daily living ("not at all [0]" to "very much [4]" interference) [20-22]. Strong evidence demonstrates the psychometric properties of the PRO-CTCAE ${ }^{\text {ma }}$ Numbness and Tingling Severity and Interference Items [20-24]. A 0-10 numerical rating scale was used to measure participants' worst CIPN pain intensity score over the past 7 days $(0=$ "No pain," $10=$ "Pain as bad as you can imagine"). Participants who reported PRO-CTCAE ${ }^{\mathrm{TN}}$ numbness and tingling severity or interference item scores $\geq 1 / 4$ and/or 0 10 numerical rating scale of worst CIPN pain intensity scores $\geq 4 / 10$ were prompted to complete additional questions asking about the location, duration, characteristics, and/or functional limitations associated with CIPN. The follow up screening questions were created by the study team using results from qualitative analyses published in the literature [6, 25]. Lastly, the QLQCIPN20 sensory (nine items) subscale measures patients' self-reported severity of numbness, tingling, and pain in the hands/feet, while the motor subscale (eight items) measures patients' self-reported functional limitations associated with CIPN symptoms (0-100 transformed score, higher scores $=$ worse severity) [26]. Several studies support the psychometric properties of the QLQCIPN20 sensory and motor subscales [23, 27, 28].

\section{Electronic medical record abstraction}

Study staff abstracted clinicians' documentation (yes/no) of CIPN assessment (i.e., numbness, tingling, pain, deep tendon reflexes, vibration sensibility, CIPN functional deficits, and functional motor assessments) and CIPN management (i.e., pharmacological or non-pharmacological treatment, continue to monitor, dose reduction, referral to subspecialty). Study staff also abstracted information about patients' cancer treatment-related information, such as diagnosis, stage, chemotherapy type, pain medication use, comorbid conditions associated with increased CIPN risk (e.g., high body mass index $[18,29,30]$ or diabetes $[17,18])$, and prior neurotoxic chemotherapy exposure. All medical record abstraction was conducted by the principal investigator and two study staff members. All identified discrepancies were resolved between the principal investigator and study staff.

\section{Criteria for appropriate CIPN management evaluation form} Several authors (RK, ES, DB) met to evaluate the appropriateness of clinicians' CIPN management recommendations using a study-team created form. Appropriate clinician-related CIPN management was scored as yes or no (i.e., "yes" = appropriately managed CIPN given current evidence surrounding CIPN management). Clinicians were deemed to have provided appropriate management for moderate-severe CIPN (i.e., $\geq 2 / 4$ on PRO$\mathrm{CTCAE}^{\mathrm{m} \mathrm{m}}$ Numbness and Tingling Severity Item) if a recommendation for pharmacological treatment (e.g., duloxetine, gabapentin) [31], dose reduction [32], or referral to physical/occupational therapy was documented [33]. On a case-by-case basis, clinicians were also deemed to have provided appropriate management for 
moderate-severe CIPN if a recommendation to continue to monitor symptoms was documented or if recommended CIPN management was previously implemented during the study and led to a decrease in CIPN severity. For mild CIPN (PRO-CTCAE ${ }^{\mathrm{Tm}}$ Numbness and Tingling Severity $=1$ ), clinicians were also found to have provided appropriate management if the presence of CIPN and/or a recommendation to "continue to monitor" was documented. All cases where clinicians did not document CIPN when the patient reported CIPN were rated as inappropriate.

\section{Procedures}

The study consisted of two phases: the usual care phase (UCP) and algorithm phase (AP). All consented clinicians $(N=53)$ participated in both the UCP and AP, but patients $(N=162)$ either participated in the UCP $(n=81)$ or AP $(n=81)$. Patients consented to the UCP completed the CIPN patient-reported outcome measures via iPad in the waiting room prior to seeing the clinician at three consecutive clinic visits associated with neurotoxic chemotherapy (i.e., T1, T2, and T3, respectively). Patients also completed a demographics questionnaire at T1. At T3, clinicians' CIPN assessment and management documentation and patients' cancer treatment information were abstracted from the electronic medical record by study staff (T3 must have been completed within a month of neurotoxic chemotherapy completion). Clinicians completed a demographics questionnaire upon enrollment into the study.

After the UCP was completed, clinicians received additional CIPN educational materials (i.e., CIPN clinical practice guideline [31], deep-tendon reflexes and vibration sensibility training video, patient-friendly resources about neuropathy safety [34]) and a PowerPoint presentation from the principal investigator about how to use the algorithm (i.e., in-person at faculty meeting or email). During the AP phase, an additional 81 patients were consented. The study procedures were the same as the UCP, except that the survey software generated a color-coded CIPN summary based on the CIPN patient-reported outcome scores (i.e., PRO-CTCAE ${ }^{\mathrm{Tm}}$ items, 0-10 numerical rating scale of worst CIPN, and follow up questions) and the CIPN algorithm at every clinic visit (i.e., T1, T2, and T3). Study staff printed the CIPN summary (Fig. 1) and algorithm (Fig. 2) and delivered the materials to the clinician (patients received the CIPN summary only) prior to each clinic visit. The CIPN algorithm incorporated recommended CIPN assessment approaches [32, 35] and evidence-based (i.e., duloxetine) [31] or promising management strategies for CIPN [36, 37]. Clinicians were instructed to use the CIPN summary and algorithm for CIPN symptom assessment and management at their discretion. Clinicians completed measures related to feasibility, acceptability, and satisfaction with CIPN algorithm use after the AP was complete.

\section{Statistical considerations}

The primary objectives were to evaluate the impact of the CIPN algorithm on changes in clinicians' CIPN assessment documentation frequency and adherence to evidence-based CIPN management. The secondary aims were to explore the impact of algorithm implementation on changes in patients' CIPN symptom severity in

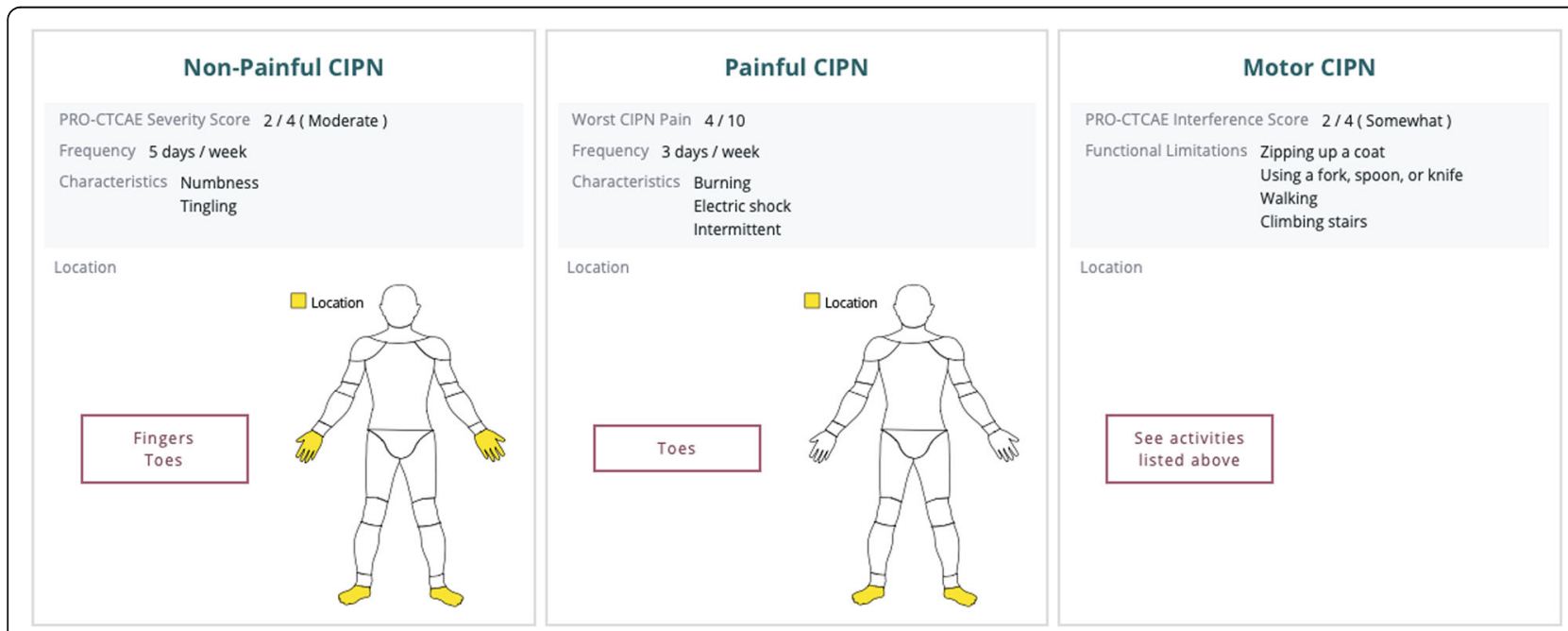

Fig. 1 Chemotherapy-Induced Peripheral Neuropathy Symptom Summary Report. The figure describes a sample symptom summary report. The summary report describes the severity, duration, characteristics, and location (i.e., body map) of non-painful and painful CIPN symptoms. In addition, the report describes the degree that CIPN symptoms interfere with activities of daily living 


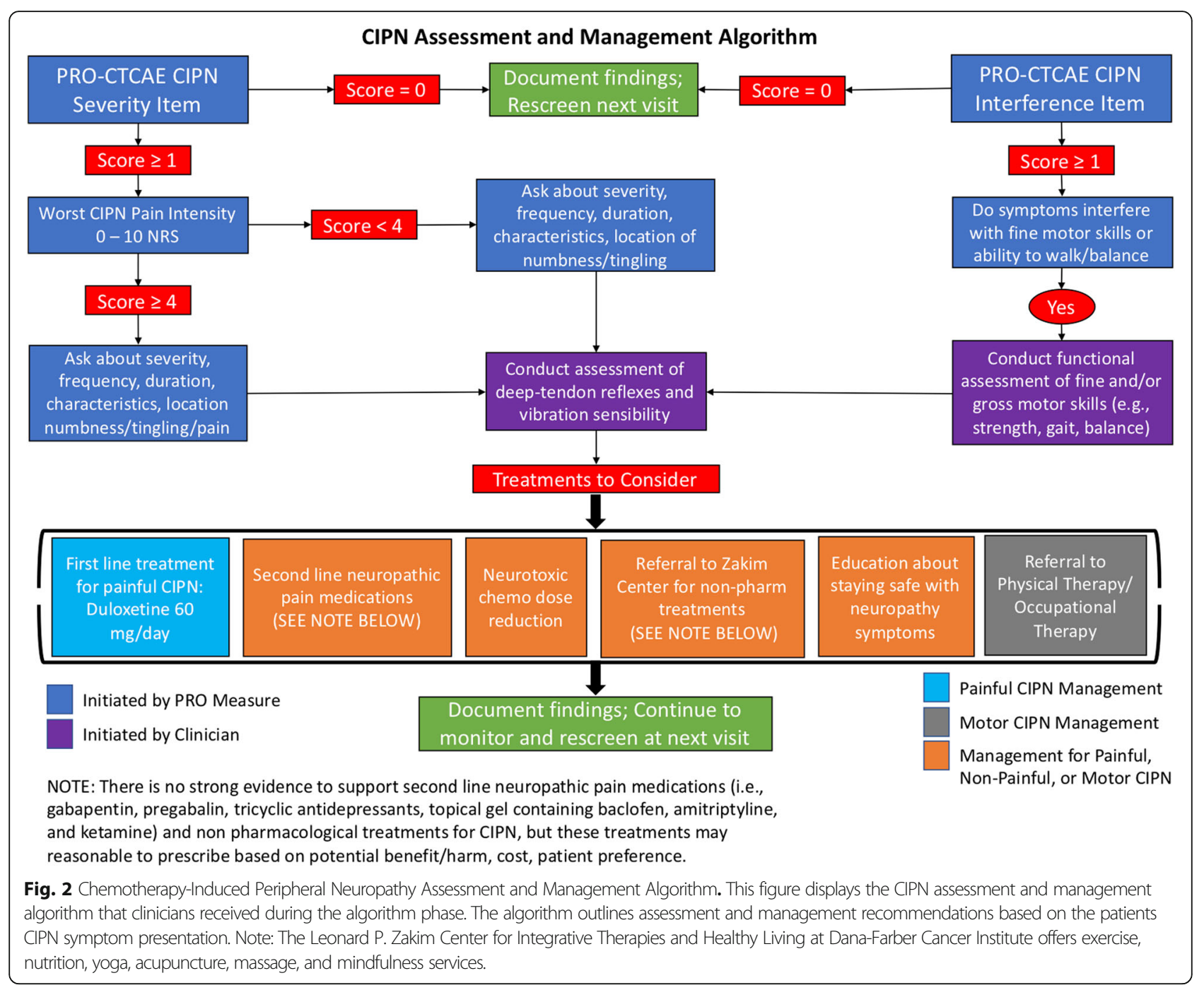

comparison to the UCP and to explore clinicians' perspectives of acceptability and satisfaction with the algorithm. It was estimated that the rate of clinicians' CIPN assessment documentation and adherence to evidencebased CIPN management would be approximately $30-$ $60 \%$ under UCP at T3 [12], and approximately $60 \%$ of patients would experience actionable CIPN (e.g., PRO$\mathrm{CTAE}^{\mathrm{m}}$ Numbness and Tingling Severity $\geq 1 / 4$ ) at T3. Assuming a $15-30 \%$ improvement in the AP, 48 patients (total 96) with actionable CIPN per group, the halfwidth of a 2 -sided $90 \%$ confidence interval (CI) for the improvement in clinicians' CIPN assessment documentation and adherence to evidence-based CIPN management ranged from 0.12 to 0.19 .

An index describing clinicians' frequency of numbness, tingling, and CIPN pain intensity was constructed to evaluate the effect of the algorithm on changes in common CIPN patient-reported outcomes (e.g., if a clinician only documented numbness, the index would be $1 / 3=$ 0.33). The rate of clinicians' CIPN assessment documentation and adherence to evidence-based management for actionable CIPN (i.e., mild or moderate-severe, respectively) at T3 were compared using Pearson's chi-squared test for equality of proportions between the UCP and AP.

The mean difference in QLQ-CIPN20 sensory and motor subscale and worst CIPN pain intensity score changes from T1-T3 between the UCP and AP were compared using two sample t-tests. To determine metrics related to feasibility, acceptability, and satisfaction of algorithm implementation, we described the number of times study staff provided the clinicians with the algorithm at each clinic visit and clinicians' scores on the two-item feasibility questionnaire and Adapted Acceptability E-Scale. All analyses were conducted using data from participants who completed the measures specific to each analysis and no missing data were imputed. 


\section{Results}

\section{Demographic characteristics}

Patient recruitment occurred from June 2018 to November 2019. A total of 162 patients were consented to the study $(n=81 \mathrm{UCP} ; n=81 \mathrm{AP})$ and 142 patients $(n=70$ $\mathrm{UCP}, n=72 \mathrm{AP})$ were evaluable for the primary or secondary analyses (Fig. 3). Table 1 describes the demographic characteristics of patients who were deemed evaluable for the primary or secondary analyses. Clinician recruitment occurred between 5/15/2018 and 7/26/ 2019. Of the 88 clinicians invited to participate in the study, 53 consented, 14 declined, and 21 did not respond to our inquiry. The consented clinicians (physician: 54.7\%; nurse practitioner: 39.6\%; physician assistant: $5.7 \%)$ were from the breast $(45.3 \%)$, gastrointestinal (34\%), and multiple myeloma (20.7\%) outpatient centers. Clinicians were a median $44($ Range $=29-74)$ years old at the time of consent and majority were female (62.3\%) and White (86.8\%). T3 notes of 42/53 consented clinicians $(79.2 \%)$ were reviewed (20 clinicians in both phases, 11 clinicians in the UCP only, and 11 clinicians in the AP only).

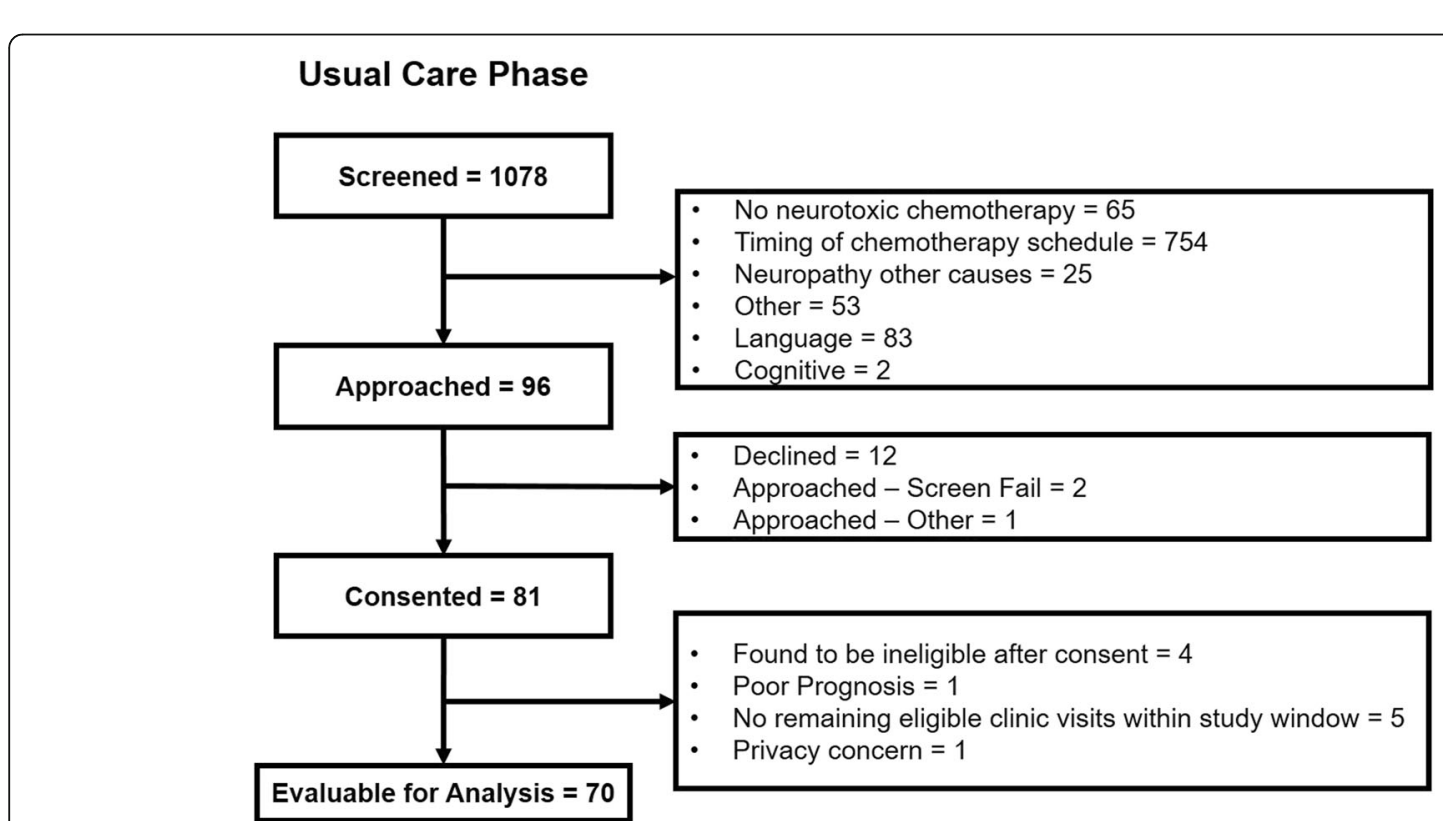

\section{Algorithm Phase}

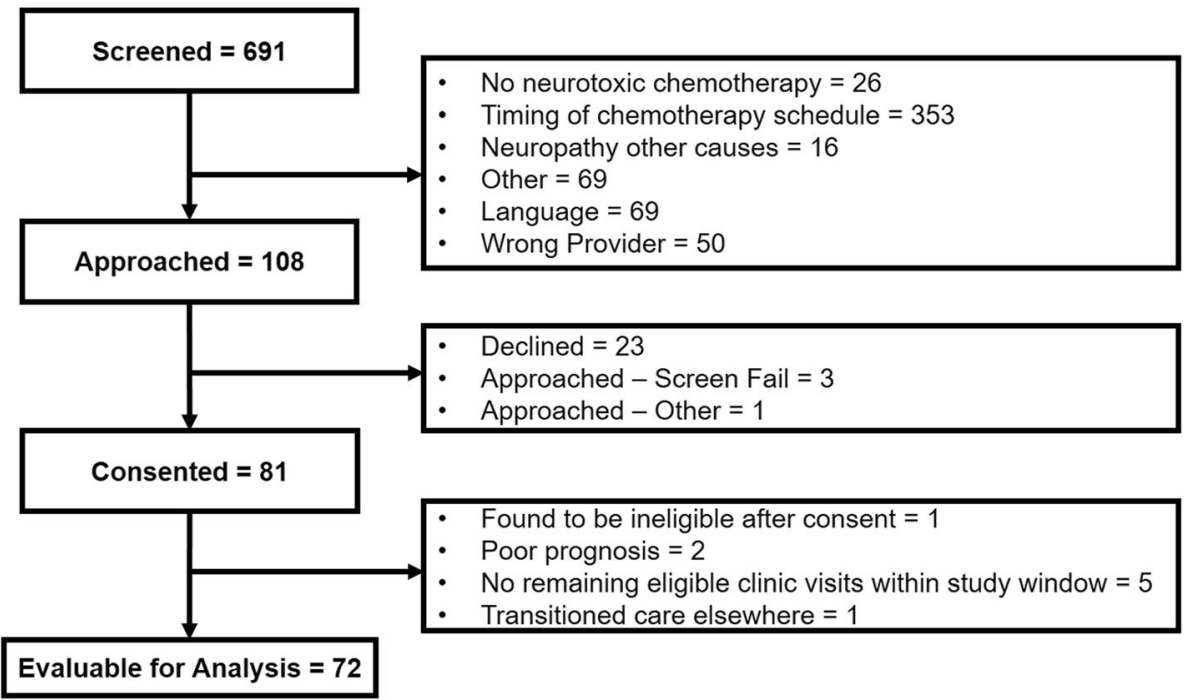

Fig. 3 Participant Flow Diagram. This figure describes patients' progress through the usual care and algorithm phases, respectively 
Table 1 Patient Demographic and Cancer Treatment-related Characteristics

\begin{tabular}{|c|c|c|c|}
\hline \multirow[t]{2}{*}{ Characteristics } & \multicolumn{3}{|l|}{ Frequency (\%) } \\
\hline & Usual Care $(N=70)$ & Algorithm $(N=72)$ & Total $(N=142)$ \\
\hline \multicolumn{4}{|l|}{ Age at T1 } \\
\hline Median (Range) & $56.5(30-80)$ & $57.5(27-79)$ & $57(27-80)$ \\
\hline \multicolumn{4}{|l|}{ Sex } \\
\hline Male & $21(30 \%)$ & $27(37.5 \%)$ & $48(33.8 \%)$ \\
\hline Female & 49 (70\%) & $45(62.5 \%)$ & $94(66.2 \%)$ \\
\hline \multicolumn{4}{|l|}{ Race } \\
\hline Asian & $3(4.3 \%)$ & $3(4.2 \%)$ & $6(4.2 \%)$ \\
\hline White & $62(88.6 \%)$ & $66(91.6 \%)$ & $128(90.2 \%)$ \\
\hline Black & $5(7.1 \%)$ & $3(4.2 \%)$ & $8(5.6 \%)$ \\
\hline \multicolumn{4}{|l|}{ Ethnicity $(n=141)$} \\
\hline Hispanic & $2(2.9 \%)$ & $3(4.2 \%)$ & $5(3.5 \%)$ \\
\hline Non-Hispanic White & $68(97.1 \%)$ & $68(95.8 \%)$ & $136(96.5 \%)$ \\
\hline \multicolumn{4}{|l|}{ Education } \\
\hline Did not complete high school & $3(4.3 \%)$ & $1(1.4 \%)$ & $4(2.8 \%)$ \\
\hline Completed high school & $6(8.6 \%)$ & $4(5.6 \%)$ & $10(7.1 \%)$ \\
\hline Some college or technical training & $20(28.5 \%)$ & $15(20.8 \%)$ & $35(24.6 \%)$ \\
\hline University undergraduate training & $21(30 \%)$ & $26(36.1 \%)$ & $47(33.1 \%)$ \\
\hline University post graduate degree & $20(28.6 \%)$ & $26(36.1 \%)$ & $46(32.4 \%)$ \\
\hline \multicolumn{4}{|l|}{ Marital Status } \\
\hline Single & $5(7.1 \%)$ & $9(12.5 \%)$ & $14(9.9 \%)$ \\
\hline Married/Partnered & $57(81.5 \%)$ & $53(73.6 \%)$ & $110(77.5 \%)$ \\
\hline Separated & 0 & $1(1.4 \%)$ & $1(0.7 \%)$ \\
\hline Divorced & $5(7.1 \%)$ & $3(4.2 \%)$ & $8(5.6 \%)$ \\
\hline Widowed & $3(4.3 \%)$ & $6(8.3 \%)$ & $9(6.3 \%)$ \\
\hline \multicolumn{4}{|l|}{ Employment Status } \\
\hline Working Full-Time & $26(37.1 \%)$ & $28(38.9 \%)$ & $54(38 \%)$ \\
\hline Working Part-Time & $10(14.3 \%)$ & $5(6.9 \%)$ & $15(10.6 \%)$ \\
\hline Working at home & $1(1.4 \%)$ & $1(1.4 \%)$ & $2(1.4 \%)$ \\
\hline Working, but on medical leave & 9 (12.9\%) & $10(13.9 \%)$ & $19(13.4 \%)$ \\
\hline Not working & $3(4.3 \%)$ & $11(15.3 \%)$ & $14(9.9 \%)$ \\
\hline Retired & $21(30 \%)$ & $17(23.6 \%)$ & $38(26.7 \%)$ \\
\hline \multicolumn{4}{|l|}{ Computer Use $(n=139)$} \\
\hline About once per month & $3(4.3 \%)$ & $1(1.4 \%)$ & $4(2.9 \%)$ \\
\hline About once per week & $4(5.8 \%)$ & $2(2.9 \%)$ & $6(4.3 \%)$ \\
\hline More than once per week & $62(89.9 \%)$ & 67 (95.7\%) & $129(92.8 \%)$ \\
\hline \multicolumn{4}{|l|}{ Cancer Type } \\
\hline Breast & $30(42.8 \%)$ & $22(30.5 \%)$ & $52(36.6 \%)$ \\
\hline Gastrointestinal & $34(48.6 \%)$ & $39(54.2 \%)$ & $73(51.4 \%)$ \\
\hline Multiple Myeloma & $4(5.7 \%)$ & $11(15.3 \%)$ & $15(10.6 \%)$ \\
\hline Multiple & $2(2.9 \%)$ & 0 & $2(1.4 \%)$ \\
\hline \multicolumn{4}{|l|}{ Cancer Name } \\
\hline Breast & $30(42.8 \%)$ & $22(30.6 \%)$ & $52(36.6 \%)$ \\
\hline Colorectal & 16 (22.9\%) & 25 (34.7\%) & 41 (28.9\%) \\
\hline
\end{tabular}


Table 1 Patient Demographic and Cancer Treatment-related Characteristics (Continued)

\begin{tabular}{|c|c|c|c|}
\hline \multirow[t]{2}{*}{ Characteristics } & \multicolumn{3}{|l|}{ Frequency (\%) } \\
\hline & Usual Care $(N=70)$ & Algorithm $(N=72)$ & Total $(N=142)$ \\
\hline Multiple Myeloma & $4(5.7 \%)$ & $10(13.9 \%)$ & $14(9.9 \%)$ \\
\hline Pancreatic & $6(8.6 \%)$ & $6(8.3 \%)$ & $12(8.5 \%)$ \\
\hline Esophageal & $7(10 \%)$ & $3(4.2 \%)$ & $10(7.0 \%)$ \\
\hline Other gastrointestinal ${ }^{a}$ & $5(7.1 \%)$ & $5(6.9 \%)$ & $10(7.0 \%)$ \\
\hline Breast and Colorectal & $2(2.9 \%)$ & 0 & $2(1.4 \%)$ \\
\hline Multiple Myeloma and Breast & 0 & $1(1.4 \%)$ & $1(0.7 \%)$ \\
\hline \multicolumn{4}{|l|}{ Cancer Stage } \\
\hline Stage I & $10(14.3 \%)$ & $10(13.9 \%)$ & $20(14.1 \%)$ \\
\hline Stage ॥ & $16(22.9 \%)$ & $12(16.7 \%)$ & $28(19.7 \%)$ \\
\hline Stage III & $23(32.8 \%)$ & $19(26.4 \%)$ & $42(29.6 \%)$ \\
\hline Stage IV Metastatic & $12(17.1 \%)$ & $21(29.1 \%)$ & $33(23.2 \%)$ \\
\hline Unknown/Not reported & $9(12.9 \%)$ & $10(13.9 \%)$ & 19 (13.4\%) \\
\hline \multicolumn{4}{|l|}{ Chemotherapy Type } \\
\hline Taxane & $33(47.1 \%)$ & $18(25 \%)$ & 51 (35.9\%) \\
\hline Platinum & $32(45.7 \%)$ & $39(54.1 \%)$ & $71(50 \%)$ \\
\hline Bortezomib & $2(2.9 \%)$ & $3(4.2 \%)$ & $5(3.5 \%)$ \\
\hline Vinca Alkaloid & $1(1.4 \%)$ & 0 & $1(0.7 \%)$ \\
\hline Multiple & $2(2.9 \%)$ & $12(16.7 \%)$ & $14(9.9 \%)$ \\
\hline \multicolumn{4}{|l|}{ Chemotherapy Name } \\
\hline Docetaxel & $2(2.9 \%)$ & $3(4.2 \%)$ & $5(3.5 \%)$ \\
\hline Docetaxel + Carboplatin & 0 & $1(1.4 \%)$ & $1(0.7 \%)$ \\
\hline Docetaxel + Carboplatin + Abraxane & 0 & $1(1.4 \%)$ & $1(0.7 \%)$ \\
\hline Paclitaxel & $31(44.2 \%)$ & $15(20.8 \%)$ & $46(32.4 \%)$ \\
\hline Paclitaxel + Carboplatin & 0 & $2(2.8 \%)$ & $2(1.4 \%)$ \\
\hline Oxaliplatin & $30(42.8 \%)$ & $39(54.1 \%)$ & $69(48.6 \%)$ \\
\hline Cisplatin & $2(2.9 \%)$ & 0 & $2(1.4 \%)$ \\
\hline Bortezomib & $2(2.9 \%)$ & $3(4.2 \%)$ & $5(3.5 \%)$ \\
\hline Vinorelbine & $1(1.4 \%)$ & 0 & $1(0.7 \%)$ \\
\hline Bortezomib + Lenalidomide & $2(2.9 \%)$ & $7(9.7 \%)$ & $9(6.4 \%)$ \\
\hline Bortezomib + Pomalidomide & 0 & $1(1.4 \%)$ & $1(0.7 \%)$ \\
\hline \multicolumn{4}{|l|}{ Neurotoxic Chemotherapy Duration at T3 } \\
\hline Received less than $1 / 3$ of planned treatment & $4(5.7 \%)$ & $11(15.3 \%)$ & $15(10.6 \%)$ \\
\hline Received at least $1 / 3$ of planned treatment & $21(30 \%)$ & $27(37.5 \%)$ & $48(33.8 \%)$ \\
\hline Received at least $2 / 3$ of planned treatment & $34(48.6 \%)$ & $31(43 \%)$ & $65(45.8 \%)$ \\
\hline Completed treatment & $11(15.7 \%)$ & $3(4.2 \%)$ & $14(9.8 \%)$ \\
\hline \multicolumn{4}{|c|}{ Comorbid Conditions Associated with increased Neuropathy Risk } \\
\hline Yes & $27(38.6 \%)$ & $42(58.3 \%)$ & $69(48.6 \%)$ \\
\hline None $^{b}$ & $43(61.4 \%)$ & 30 (41.7\%) & $73(51.4 \%)$ \\
\hline \multicolumn{4}{|l|}{ Previous Neurotoxic Chemotherapy } \\
\hline Yes & $10(14.3 \%)$ & $5(6.9 \%)$ & $15(10.6 \%)$ \\
\hline No & $60(85.7 \%)$ & $67(93.1 \%)$ & $127(89.4 \%)$ \\
\hline \multicolumn{4}{|c|}{ Neurotoxic Chemotherapy Dose Reduction During Study } \\
\hline Yes & 20 (28.6\%) & $27(37.5 \%)$ & $47(33.1 \%)$ \\
\hline
\end{tabular}


Table 1 Patient Demographic and Cancer Treatment-related Characteristics (Continued)

\begin{tabular}{|c|c|c|c|}
\hline \multirow[t]{2}{*}{ Characteristics } & \multicolumn{3}{|l|}{ Frequency (\%) } \\
\hline & Usual Care $(N=70)$ & Algorithm $(N=72)$ & Total $(N=142)$ \\
\hline No & $50(71.4 \%)$ & $45(62.5 \%)$ & $95(66.9 \%)$ \\
\hline \multicolumn{4}{|c|}{ Neurotoxic Chemotherapy Dose Reduction Rationale $(n=47)$} \\
\hline Abnormal Labs & $3(15 \%)$ & $5(18.5 \%)$ & $8(17 \%)$ \\
\hline General Poor Tolerability & $2(10 \%)$ & $2(7.4 \%)$ & $4(8.5 \%)$ \\
\hline Hypersensitivity & 0 & $1(3.7 \%)$ & $1(2.1 \%)$ \\
\hline Multiple Reasons & $2(10 \%)$ & $3(11.1 \%)$ & $5(10.6 \%)$ \\
\hline Neuropathy-Related & $7(35 \%)$ & $7(26 \%)$ & $14(30 \%)$ \\
\hline Other Cancer Treatment-Related Symptoms & $3(15 \%)$ & $4(14.8 \%)$ & $7(14.9 \%)$ \\
\hline Other Health Issues & $2(10 \%)$ & $3(11.1 \%)$ & $5(10.6 \%)$ \\
\hline Other Plans & 0 & $1(3.7 \%)$ & $1(2.1 \%)$ \\
\hline Progression & 0 & $1(3.7 \%)$ & $1(2.1 \%)$ \\
\hline Unknown & $1(5 \%)$ & 0 & $1(2.1 \%)$ \\
\hline
\end{tabular}

Table 1 describes the demographic and cancer treatment-related symptoms of enrolled patient participants that were evaluable for the primary or secondary analyses

a Other gastrointestinal malignancies included appendix, ampullary, cholangiocarcinoma, gallbladder, gastric, small bowel, cecum

${ }^{\mathrm{b}}$ Comorbid conditions that may have increased chemotherapy-induced peripheral neuropathy risk included anxiety, arthritis, depression, diabetes, fatigue, hearing loss, obesity, other neuropathy, other pain, psychological comorbidity, smoking history

\section{Primary aim}

Overall, numbness, tingling, or pain was documented by clinicians in 110/139 (79.1\%) reviewed notes at T3 (Table 2). The CIPN assessment documentation index decreased from 0.6468 (i.e., clinicians evaluated approximately $2 / 3$ CIPN symptoms on average) in the UCP to 0.5440 (i.e., clinicians evaluated approximately less than $2 / 3$ CIPN symptoms on average) in the AP at T3 ( $p=$ 0.07; $90 \%$ CI: $0.009,0.20)$. Overall, a total of 98 patients reported at least mild or greater CIPN severity at T3. The rate of appropriate CIPN management improved $12.3 \%$ from $20 / 46$ (43.5\%) patients in the UCP to $29 / 52$ (55.8\%) patients in the AP, but the change was not significant ( $p=0.31,90 \% \mathrm{CI}:-0.31,0.06)$. The frequency of appropriate mild CIPN management improved 22\% from $12 / 25$ (48\%) cases in the UCP to $21 / 30$ (70\%) cases in the AP, but the change was not significant $(p=0.17$; $90 \%$ CI: $-0.47,0.03)$. There was no improvement in the frequency of appropriate moderate-severe CIPN management documentation following algorithm implementation (UCP: 8/20 [38.1\%]; Algorithm: 8/22 [36.4\%]). Duloxetine was never prescribed to any patients reporting moderate-severe CIPN severity in either phase.

\section{Secondary aims}

There were no significant changes in patients' mean QLQ-CIPN20 sensory, QLQ-CIPN20 motor, or worst CIPN pain intensity scores between phases from $\mathrm{T} 1$ to T3 (Table 3). The algorithm was successfully delivered to clinicians prior to $207 / 216$ (95.8\%) clinic visits. Most clinicians "seldomly" or "sometimes" used the CIPN algorithm and symptom assessment summary to facilitate
CIPN symptom assessment and management during a clinic visit, while clinicians "seldomly" used the CIPN education materials study staff members emailed clinicians prior to algorithm use $(n=19)$ (Table 4). Clinicians' ratings of acceptability and satisfaction were moderate, with individual item score ranges of $1-5$ for all eight questions of the Adapted Acceptability E Scale. The highest rated item was related to how understandable the content was presented within the algorithm $($ Mean $=3.95, S D=1.13)$, while the lowest rated item pertained to how helpful the algorithm was in guiding CIPN assessment or management clinical interactions with patients $($ Mean $=2.89, S D=1.29) \quad(n=19)$ (Table 4).

\section{Discussion}

Improving CIPN assessment documentation is a twofold challenge: 1) patients and clinicians must discuss the absence or presence of CIPN and 2) clinicians must document CIPN in the electronic medical record. Results revealed that implementation of the clinician decision support algorithm did not significantly improve clinicians' documentation of CIPN symptom assessment. The observed CIPN assessment documentation frequency in the UCP (e.g., 83.6 and 79.1\% documented numbness and tingling, respectively) was considerably higher than CIPN assessment documentation frequencies reported in prior studies (Range = approximately 46 to $58 \%)[12,13]$. As such, we may have observed a ceiling effect in pre-posttest CIPN assessment documentation changes. On the other hand, clinicians' painful CIPN documentation in the UCP was low (31.3\%), but 
Table 2 Frequency of Clinicians' CIPN Assessment and Management Documentation Between the UCP and AP at T3

\begin{tabular}{|c|c|c|c|c|}
\hline \multirow[t]{2}{*}{ Assessment Documentation } & \multicolumn{4}{|c|}{ Frequency (\%) } \\
\hline & \multicolumn{2}{|c|}{ Usual Care $(N=67)^{f}$} & \multicolumn{2}{|c|}{ Algorithm $(N=72)$} \\
\hline \multicolumn{5}{|l|}{ Numbness } \\
\hline Not Documented & \multicolumn{2}{|l|}{$11(16.4 \%)$} & \multicolumn{2}{|l|}{$18(25 \%)$} \\
\hline Documented & \multicolumn{2}{|l|}{$56(83.6 \%)$} & \multicolumn{2}{|l|}{$54(75 \%)$} \\
\hline \multicolumn{5}{|l|}{ Tingling } \\
\hline Not Documented & \multicolumn{2}{|l|}{$14(20.9 \%)$} & \multicolumn{2}{|l|}{$21(29.2 \%)$} \\
\hline Documented & \multicolumn{2}{|l|}{$53(79.1 \%)$} & \multicolumn{2}{|l|}{$51(70.8 \%)$} \\
\hline \multicolumn{5}{|l|}{ CIPN Pain } \\
\hline Not Documented & \multicolumn{2}{|l|}{$46(68.7 \%)$} & \multicolumn{2}{|l|}{$60(83.3 \%)$} \\
\hline Documented & \multicolumn{2}{|l|}{$21(31.3 \%)$} & \multicolumn{2}{|l|}{$12(16.7 \%)$} \\
\hline \multicolumn{5}{|l|}{ Reflexes $(n=114)$} \\
\hline No Neuropathy Present ${ }^{\mathrm{a}}$ & \multicolumn{2}{|l|}{19} & \multicolumn{2}{|l|}{6} \\
\hline Not Documented & \multicolumn{2}{|l|}{$46(95.8 \%)$} & \multicolumn{2}{|l|}{$61(92.4 \%)$} \\
\hline Documented & \multicolumn{2}{|l|}{$2(4.2 \%)$} & \multicolumn{2}{|l|}{$5(7.6 \%)$} \\
\hline Vibration $(n=109)$ & & & & \\
\hline No Neuropathy Present ${ }^{\mathrm{a}}$ & 20 & & 10 & \\
\hline Not Documented & $47(100 \%)$ & & $62(100 \%)$ & \\
\hline Documented & 0 & & 0 & \\
\hline Functional Assessment $^{\mathrm{b}}(n=114)$ & & & & \\
\hline No Neuropathy Present ${ }^{a}$ & 20 & & 5 & \\
\hline Not Documented & $30(63.8 \%)$ & & $41(61.2 \%)$ & \\
\hline Documented & $17(36.2 \%)$ & & $26(38.8 \%)$ & \\
\hline Functional Deficits ${ }^{\complement}(n=109)$ & & & & \\
\hline No Neuropathy Present ${ }^{\mathrm{a}}$ & 20 & & 10 & \\
\hline Not Documented & $36(76.6 \%)$ & & $49(79 \%)$ & \\
\hline Documented & $11(23.4 \%)$ & & $13(21 \%)$ & \\
\hline Appropriate Management of Mild CIPN PRO-CTCAE ${ }^{\mathrm{TM}}=1$ & Usual Care & & Algorithm & \\
\hline & Yes $(n=12)$ & No $(n=13)$ & Yes $(n=21)$ & No $(n=9)$ \\
\hline Continue to monitor & $5(41.7 \%)$ & 0 & $5(23.8 \%)$ & 0 \\
\hline Dose Reduction & $1(8.3 \%)$ & 0 & $2(9.5 \%)$ & 0 \\
\hline No new management offered; provider documented presence of CIPN & $6(50 \%)$ & 0 & $14(66.7 \%)$ & 0 \\
\hline No documentation of neuropathy & 0 & $8(61.5 \%)$ & 0 & $4(44.4 \%)$ \\
\hline No new management offered; Discrepancy in severity of provider documented and patient-reported CIPN ${ }^{d}$ & 0 & $5(38.5 \%)$ & 0 & $5(55.6 \%)$ \\
\hline Appropriate Management of Moderate-Severe CIPN (PRO-CTCAE ${ }^{\mathrm{Tm}} \geq 2$ ) & Usual Care & & Algorithm & \\
\hline & Yes $(n=8)$ & No $(n=13)$ & Yes $(n=8)$ & No $(n=14)$ \\
\hline Continue to monitor & 0 & $2(15.4 \%)$ & $4(50 \%)$ & 0 \\
\hline Dose Reduction & $4(50 \%)$ & 0 & $3(37.5 \%)$ & 0 \\
\hline No documentation of neuropathy & 0 & 0 & 0 & $4(28.6 \%)$ \\
\hline No new management offered ${ }^{e}$ & $2(25 \%)$ & $11(84.6 \%)$ & $1(12.5 \%)$ & $10(71.4 \%)$ \\
\hline Pharmacological Treatment Offered & $2(25 \%)$ & 0 & 0 & 0 \\
\hline
\end{tabular}

Table 2 describes clinicians' frequency of CIPN assessment documentation and adherence to evidence-based CIPN management at T3 in both the usual care and algorithm phases

a If the clinician stated that no neuropathy was present in the reviewed note, we did not code the absence of documentation related to reflexes, vibration, functional assessment, or functional deficits as "Not Documented." Instead, we removed such instances from the sample size for the variables of reflexes, vibration, functional assessment, or functional deficits. Thus, the frequency of documentation of reflexes, vibration, functional assessment, or functional deficits is calculated from the number of instances in which the clinician documented that neuropathy was present

${ }^{b}$ Included the documentation of gross motor (e.g., walking or balance observations), fine motor (e.g., picking up a penny), or strength tests conducted by the clinician Included the absence or presence of any limitations in activities of daily living associated with chemotherapy-induced peripheral neuropathy symptoms (e.g., typing, walking, opening jars, writing, weakness, fine motor coordination) documented by the clinician

${ }^{\mathrm{d}}$ Patient reported mild neuropathy, but clinician documented that no neuropathy was present

'There were three instances where the clinician did not recommend any new CIPN management, but the cases were rated as appropriate CIPN management: 1) the clinician dose reduced neurotoxic chemotherapy prior to T3 and CIPN scores decreased from T2 to T3, 2) the clinician prescribed gabapentin prior to T3 and worst CIPN pain intensity decreased from T2 to T3, and 3) the clinician dose reduced neurotoxic chemotherapy two times prior to T3 and CIPN severity decreased from T1 to T3

${ }^{\mathrm{f}} \mathrm{N}=67$ instead of 70 because three patient participants did not see a consented clinician at T3 
Table 3 T1 - T3 Changes in CIPN Patient-Reported Outcomes Between Study Phases

\begin{tabular}{|c|c|c|c|}
\hline Outcomes & Usual Care Mean (SD) & Algorithm Mean (SD) & Contrast Between Groups ${ }^{f}$ \\
\hline \multicolumn{4}{|c|}{ Sensory CIPN Severity } \\
\hline $\mathrm{T} 1^{\mathrm{a}}$ & $8.21(11.77)$ & $7.48(9.2)$ & \multirow{3}{*}{$\begin{array}{l}t=0.06 \\
p=0.95 \\
90 \% C l=-2.64,2.83 \\
n=136\end{array}$} \\
\hline $\mathrm{T} 2^{\mathrm{a}}$ & $12.62(12.83)$ & $9.47(8.74)$ & \\
\hline$T 3^{c}$ & $12.68(12.38)$ & $11.21(11.45)$ & \\
\hline \multicolumn{4}{|c|}{ Motor CIPN Severity } \\
\hline $\mathrm{T} 1^{\mathrm{a}}$ & $5.38(8.7)$ & $4.93(6.42)$ & \multirow{3}{*}{$\begin{array}{l}t=0.12 \\
p=0.90 \\
90 \% C l=-2.28,2.64 \\
n=136\end{array}$} \\
\hline$T 2^{b}$ & $7.32(10.57)$ & $7.89(8.91)$ & \\
\hline$T 3^{c}$ & $8.98(11.84)$ & $8.04(9.33)$ & \\
\hline \multicolumn{4}{|c|}{ Worst CIPN Pain Intensity } \\
\hline $\mathrm{T}^{\mathrm{d}}$ & $1.38(2.17)$ & $1.43(1.79)$ & \multirow{3}{*}{$\begin{array}{l}t=0.18 \\
p=0.86 \\
90 \% C l=-0.53,0.65 \\
n=134\end{array}$} \\
\hline $\mathrm{T} 2^{\mathrm{e}}$ & $2.01(2.54)$ & $1.97(2.3)$ & \\
\hline$T 3^{c}$ & $2.05(2.34)$ & $1.90(2.01)$ & \\
\hline
\end{tabular}

Table 3 describes changes in sensory CIPN severity, motor CIPN severity, and worst CIPN pain intensity severity from T1 to T3 between study phases

${ }^{\mathrm{a}} N=69$ Usual Care, $N=71$ Algorithm

${ }^{\mathrm{b}} \mathrm{N}=69$ Usual Care, $N=70$ Algorithm

${ }^{c} N=66$ Usual Care, $N=72$ Algorithm

${ }^{\mathrm{d}} N=69$ Usual Care, $N=69$ Algorithm

${ }^{\mathrm{e}} N=68$ Usual Care, $N=71$ Algorithm

fStatistical test to determine whether the change from $\mathrm{T} 1$ to $\mathrm{T} 3$ was different between study phases

clinicians' painful CIPN documentation did not improve following algorithm implementation (16.7\%). Improving the identification of painful CIPN is critical as the firstline treatment recommendation of duloxetine for painful CIPN was determined based on evidence suggesting that duloxetine significantly improved average CIPN pain intensity in comparison to placebo [38].

Study results demonstrated that availability of the algorithm did not significantly improve clinicians' management of mild or moderate-severe CIPN. Although, availability of the algorithm improved clinicians' management of mild CIPN by $22 \%$, mainly via increased identification and monitoring of CIPN. On the other hand, duloxetine was never prescribed for individuals with moderate-severe CIPN. It has been 7 years since the publication of the trial by Smith et al. (2013) that demonstrated the efficacy of duloxetine for chronic painful CIPN [38]; and 6 years since the publication of the clinical practice guideline suggesting duloxetine as a first-line treatment for painful CIPN [31], however, barriers to duloxetine prescription still persist and should be explored in further research. Our findings are similar with those of Knoerl et al. (2018), who demonstrated that the implementation of an electronic care planning system improved breast oncology nurse practitioners' management of non-painful CIPN (e.g., mainly via an increase in the number of recommendations to "continue to monitor"), but not painful CIPN (e.g., no recommendation of analgesic such as duloxetine) [12]. Finally, as expected with the minimal improvements in clinicians' CIPN management behaviors, there were no changes in
CIPN severity between patients enrolled to the UCP or AP.

There are several explanations as to why algorithm implementation did not significantly influence clinicians' CIPN assessment or management behaviors. Despite the high feasibility of algorithm delivery to clinicians, most clinicians "seldomly" or "sometimes" used the algorithm and/or associated educational materials to guide CIPN assessment or management. Clinicians may not have regularly used the algorithm because of a lack of time in the clinic or they found the algorithm-related assessment and management steps burdensome to implement. Moreover, the implementation plan for algorithm delivery was suboptimal. Colquhoun et al. (2017) conducted a systematic review to determine strategies for designing interventions intended to influence clinician healthcare behaviors and concluded that there were four steps critical to designing such interventions: 1) identifying barriers, 2) targeting intervention components to barriers, 3) theory selection, and 4) obtaining clinician feedback [39]. While the algorithm intervention was designed to target barriers identified in prior research [12-14], the current intervention was not guided by implementation theory and clinicians' perspectives of acceptability and satisfaction with the intervention were not integrated prior to intervention implementation.

Due to the clinicians' low usage and acceptability and satisfaction ratings of the algorithm in the current study, future research should be directed towards the testing of theory-based implementation interventions to improve the assessment and management of CIPN. Derived from 
Table 4 Clinician Acceptability E - Scale and Feasibility Questionnaire Results $(N=19)$

\begin{tabular}{|c|c|}
\hline Adapted Acceptability E - Scale ${ }^{a}$ & $\begin{array}{l}\text { Mean (SD, } \\
\text { Range) }\end{array}$ \\
\hline $\begin{array}{l}\text { Did use of the Algorithm help you identify appropriate areas of concern related to the assessment and/or management of CIPN } \\
\text { symptoms? }\end{array}$ & $3.05(1.39,1-5)$ \\
\hline $\begin{array}{l}\text { Did use of the Algorithm help guide clinical interactions with patients related to the assessment and management of CIPN } \\
\text { symptoms? }\end{array}$ & $2.89(1.29,1-5)$ \\
\hline $\begin{array}{l}\text { Was the Algorithm helpful in promoting communication between you and your patients related to the assessment and } \\
\text { management of CIPN symptoms? }\end{array}$ & $3.21(1.4,1-5)$ \\
\hline Was the Algorithm helpful in identifying areas of need or symptoms related to CIPN? & $3.11(1.15,1-5)$ \\
\hline $\begin{array}{l}\text { Was use of the Algorithm helpful in promoting your knowledge related to the assessment and/or management of CIPN } \\
\text { symptoms? }\end{array}$ & $2.95(1.13,1-5)$ \\
\hline How understandable was the content presented within the Algorithm? & $3.95(1.13,1-5)$ \\
\hline How easy was it to use the Algorithm during your clinical interactions with patients? $(n=18)$ & $3.39(1.14,1-5)$ \\
\hline Overall, how would you rate your satisfaction with the Algorithm? & $3.11(0.94,1-5)$ \\
\hline
\end{tabular}

\section{Feasibility Questionnaire ${ }^{\mathrm{b}}$}

When you received the Chemotherapy-Induced Peripheral Neuropathy (CIPN) Symptom Assessment Summary (sheet displaying pa- 2.58 (0.9, 1-4) tients' CIPN severity scores) and the CIPN Assessment and Management Algorithm, how often did you use the CIPN Symptom Assessment Summary or Assessment and Management Algorithm to aid you in the assessment and management of CIPN during those particular clinic visits?

We sent you several other education materials (i.e., neuropathy safety information, vibration sensibility and deep-tendon reflexes training video, CIPN clinical practice guideline) via email before you began using the CIPN Assessment and Management Algorithm. You most likely received this email around February or March 2019. From the time that you received the email containing the materials, did you review or use the materials we provided to you to aid in the assessment and/or management of CIPN symptoms?

Table 4 describes clinicians' mean scores on the Adapted Acceptability E - Scale and Feasibility Questionnaire in regard to the CIPN algorithm at the end of the study

${ }^{\mathrm{a}}$ The Adapted Acceptability E - Scale items were scored from 1 to 5, with higher scores indicating greater acceptability or satisfaction

${ }^{\mathrm{b}}$ The Feasibility Questionnaire items were scored from 1 to 5 (i.e., $1=$ Never, $2=$ Seldom, $3=$ Sometimes, $4=$ Frequently, $5=$ Always)

the Expert Recommendations for Implementing Change (identified 73 implementation strategies and associated definitions) [40, 41] and the Conceptual Model of Evidence-Based Practice Implementation [42], the Strategic Implementation Framework recommends varying implementation strategies along the oncology care change process: 1) Setting the Stage (e.g., create guidelines, identify barriers), 2) Active Implementation (e.g., develop educational materials and methods to monitor intervention delivery), and 3) Monitor, Support, Sustain (e.g., provide reminders or coaching) [43]. With the Strategic Implementation Framework in mind, interventions designed to target clinician-related CIPN assessment and management behavior change must incorporate key stakeholders' feedback (e.g., clinicians) regarding barriers to assessing and managing CIPN early in the intervention design process and provide ongoing feedback and support during intervention implementation [43]. For patients, potential intervention targets may include previously identified enablers and deterrents to patient reporting of CIPN [44]. Factors that enabled patients to report CIPN to clinicians included positive relationships with health care team members, adequate amount of time to discuss CIPN during appointments, potential to talk with the health care team between in-person clinic appointments, and CIPN education prior to treatment [44]. Conversely, factors that deterred patients from reporting CIPN included perceived need to complete the entire chemotherapy regimen, fear of chemotherapy withdrawal due to CIPN, and lack of education surrounding the potential for chronic CIPN [44].

\section{Limitations}

There are several limitations to this research. First, the generalizability of our findings is limited because the patient and clinician samples were homogenous in race and ethnicity and recruited from one academic cancer center. Second, differences in CIPN assessment and management documentation frequency between phases may be influenced by the number of notes written by particular clinicians within each phase (e.g., some clinicians consistently never documented CIPN) or the number of times each clinician received the algorithm during the study (e.g., algorithm exposure or dose). Third, changes in CIPN assessment or management documentation by clinicians may have been a result of external factors to the study due to the lack of a true control group (e.g., clinician-study staff interaction regarding CIPN assessment; increased awareness of CIPN standards of care not related to algorithm use). Fourth, 
between-group changes in patients' CIPN severity over time was confounded by the eligibility criteria (e.g., patients were receiving various neurotoxic chemotherapy types/dosages and recruited at different time points during their neurotoxic chemotherapy regimens). Fifth, it is possible that the methods used to measure changes in clinicians' CIPN assessment and management documentation may not have been sensitive to the unique symptom presentations associated with CIPN due to taxanes, oxaliplatin, or bortezomib. Lastly, the frequency of CIPN assessment and appropriate management observed in this study may not have been representative of actual clinical practice because we did not audio record patient-clinician outpatient encounters and decisions regarding the appropriateness of clinicians' CIPN management actions at T3 were made based on patients' selfreported CIPN severity and clinicians' CIPN documentation only.

\section{Conclusion}

Implementation of a clinician-decision support algorithm did not significantly improve clinicians' CIPN assessment documentation or use of evidence-based management strategies when providing care to patients receiving neurotoxic chemotherapy at breast, gastrointestinal, or multiple myeloma oncology outpatient centers. Reasons for the lack of algorithm-induced changes in clinicians' CIPN assessment and management behaviors included that clinicians infrequently used the algorithm or associated educational materials to assess or manage CIPN and a suboptimal intervention implementation plan. Future research should be directed toward the development and testing of theory-guided implementation interventions to improve the assessment and management of CIPN in clinical practice.

\section{Abbreviations}

AP: Algorithm Phase; CIPN: Chemotherapy-induced peripheral neuropathy; EORTC QLQ C-30: European Organisation for Research and Treatment of Cancer Quality of Life Core Questionnaire 30; PRO-CTCAE ${ }^{\mathrm{TM}}$. Patient Reported Outcomes version of the Common Terminology Criteria for Adverse Events; UCP: Usual Care Phase

\section{Acknowledgements}

We would like to acknowledge Erica Fox, Kristina Italiano, Jessica Wallar, Beatrice Benjamin, Xiaohui Yu, and Barbara Halpenny for their assistance in participant recruitment, participant data collection, and/or study management. We would like to acknowledge the clinic assistants working at the breast oncology, gastrointestinal oncology, and multiple myeloma disease centers at Dana-Farber Cancer Institute for their support with implementing the primary study. We would like to acknowledge Cindy Tofthagen for her permission to revise and test the Algorithm for Nursing Assessment and Management of Chemotherapy-Induced Peripheral Neuropathy in this study. We would like to acknowledge Traci Blonquist for her biostatistical support at the beginning of the trial. Finally, we would like to acknowledge Justin McReynolds for his technical support of the software responsible for data capture and the generation of the CIPN algorithm and patient summary.
Authors' information (optional)

Not applicable.

\section{Authors' contributions}

RK (Principal Investigator) was primarily responsible for the design and conduct of the study, interpretation of the data, and writing of the manuscript. EM and FH contributed to the analysis of the data. ES, JL, NM, KR, DB, and FH were all involved in the design and conception of the study. All authors have read and approved the final manuscript.

\section{Funding}

The study was funded by the Mittelman Integrative Oncology Family Fund. The funding source had no role in the design of the study, data collection, data analysis, or manuscript writing.

\section{Availability of data and materials}

The datasets used and/or analyzed during the current study are available from the corresponding author on reasonable request.

\section{Declarations}

\section{Ethics approval and consent to participate}

Study oversight and ethics approval was provided by the Dana-Farber/Harvard Cancer Center Office for Human Research Studies (18-049). All study participants provided written consent to participate in the trial.

\section{Consent for publication}

Not applicable.

\section{Competing interests}

The authors declare that they have no competing interests.

\section{Author details}

${ }^{1}$ Dana-Farber Cancer Institute, Boston, MA, USA. ${ }^{2}$ Department of Biostatistics and Computational Biology, Dana-Farber Cancer Institute, Boston, MA, USA.

${ }^{3}$ Medical Oncology, Dana-Farber Cancer Institute, Boston, MA, USA.

${ }^{4}$ Biobehavioral Nursing and Health Informatics, University of Washington, Seattle, WA, USA.

Received: 5 August 2020 Accepted: 24 February 2021

Published online: 06 March 2021

\section{References}

1. Argyriou AA, Kyritsis AP, Makatsoris T, Kalofonos HP. Chemotherapy-induced peripheral neuropathy in adults: a comprehensive update of the literature. Cancer Manag Res. 2014;6:135-47. http://www.ncbi.nlm.nih.gov/pubmed/24 672257.

2. Seretny M, Currie GL, Sena ES, Ramnarine S, Grant R, MacLeod MR, et al. Incidence, prevalence, and predictors of chemotherapy-induced peripheral neuropathy: a systematic review and meta-analysis. Pain. 2014;155(12):2461-70.

3. Tamburin S, Park SB, Alberti P, Demichelis C, Schenone A, Argyriou AA. Taxane and epothilone-induced peripheral neurotoxicity: From pathogenesis to treatment. J Peripher Nerv Syst. 2019;24(S2). https://onlinelibrary.wiley.com/ doi/abs/10.1111/jns.12336.

4. Staff NP, Cavaletti G, Islam B, Lustberg M, Psimaras D, Tamburin S. Platinuminduced peripheral neurotoxicity: From pathogenesis to treatment. J Peripher Nerv Syst. 2019;24(S2). https://onlinelibrary.wiley.com/doi/abs/1 0.1111/jns.12335.

5. Velasco R, Alberti P, Bruna J, Psimaras D, Argyriou AA. Bortezomib and other proteosome inhibitors - induced peripheral neurotoxicity: From pathogenesis to treatment. J Peripher Nerv Syst. 2019;24(S2). https://onlinelibrary.wiley.com/ doi/abs/10.1111/jns.12338.

6. Tanay MAL, Armes J, Ream E. The experience of chemotherapy-induced peripheral neuropathy in adult cancer patients: a qualitative thematic synthesis. Eur J Cancer Care (Engl). 2017;26(5):e12443. http://doi.wiley.com/1 $0.1111 /$ ecc. 12443 .

7. Loprinzi CL, Lacchetti C, Bleeker J, Cavaletti G, Chauhan C, Hertz DL, et al. Prevention and Management of Chemotherapy-Induced Peripheral Neuropathy in Survivors of Adult Cancers: ASCO Guideline Update. J Clin Oncol. 2020:JCO.20.01399. https://ascopubs.org/doi/10.1200/JCO.20.01399. 
8. McCrary JM, Goldstein D, Wyld D, Henderson R, Lewis CR, Park SB. Mobility in survivors with chemotherapy-induced peripheral neuropathy and utility of the 6-min walk test. J Cancer Surviv. 2019. http://link.springer.com/10.1 007/s11764-019-00769-7.

9. Winters-Stone KM, Horak F, Jacobs PG, Trubowitz P, Dieckmann NF, Stoyles $S$, et al. Falls, functioning, and disability among women with persistent symptoms of chemotherapy-induced peripheral neuropathy. J Clin Oncol. 2017;35(23):2604-12. http://www.ncbi.nlm.nih.gov/pubmed/28586243.

10. Song X, Wilson KL, Kagan J, Panjabi S. Cost of peripheral neuropathy in patients receiving treatment for multiple myeloma: a US administrative claims analysis. Ther Adv Hematol. 2019;10:204062071983902. http://journals.sagepub. com/doi/10.1177/2040620719839025.

11. Tanay MA, Armes J. Lived experiences and support needs of women who developed chemotherapy-induced peripheral neuropathy following treatment for breast and ovarian cancer. Eur J Cancer Care (Engl). 2019:e13011. http://doi. wiley.com/10.1111/ecc.13011.

12. Knoerl R, Bridges C, Smith G, Yang J, Kanzawa-Lee G, Smith E. ChemotherapyInduced Peripheral Neuropathy: Use of an Electronic Care Planning System to Improve Adherence to Recommended Assessment and Management Practices. Clin J Oncol Nurs. 2018;22(5):E134-40. http://cjon.ons.org/cjon/22/5/ chemotherapy-induced-peripheral-neuropathy-use-electronic-care-planningsystem-improve.

13. Knoerl R, Smith EML, Han A, Doe A, Scott K, Berry DL. Characterizing patient-clinician chemotherapy-induced peripheral neuropathy assessment and management communication approaches. Patient Educ Couns. 2019; 102(9):1636-43.

14. Knoerl R, Dudley WN, Smith G, Bridges C, Kanzawa-Lee G, Lavoie Smith EM. Pilot Testing a Web-Based System for the Assessment and Management of Chemotherapy-Induced Peripheral Neuropathy. Comput Inform Nurs. 2017; 35(4):201-11. https://doi.org/10.1097/CIN.0000000000000320.

15. Knoerl R, Lee D, Yang J, Bridges C, Kanzawa-Lee G, Lita Smith G, Lavoie Smith EM. Examining the Impact of a Web-Based Intervention to Promote Patient Activation in Chemotherapy-Induced Peripheral Neuropathy Assessment and Management. J Cancer Educ. 2018:33(5):1027-35. https:// doi.org/10.1007/s13187-017-1200-0.

16. Tofthagen C, Visovsky CM, Hopgood R. Chemotherapy-induced peripheral neuropathy: an algorithm to guide nursing management. Clin J Oncol Nurs. 2013;17(2):138-44. http://cjon.ons.org/cjon/17/2/chemotherapy-inducedperipheral-neuropathy

17. Hershman DL, Till C, Wright JD, Awad D, Ramsey SD, Barlow WE, et al. Comorbidities and Risk of Chemotherapy-Induced Peripheral Neuropathy Among Participants 65 Years or Older in Southwest Oncology Group Clinical Trials. J Clin Oncol. 2016;34(25):3014-22. http://www.ncbi.nIm.nih. gov/pubmed/27325863.

18. Miaskowski C, Mastick J, Paul SM, Topp K, Smoot B, Abrams G, et al. Chemotherapy-induced neuropathy in Cancer survivors. J Pain Symptom Manag. 2017;54(2):204-218.e2. http://www.ncbi.nlm.nih.gov/pubmed/28063 866.

19. Tariman JD, Berry DL, Halpenny B, Wolpin S, Schepp K. Validation and testing of the Acceptability E-scale for web-based patient-reported outcomes in cancer care. Appl Nurs Res. 2011;24(1):53-8. https://doi.org/1 0.1016/j.apnr.2009.04.003. Epub 2009 Sep 18.

20. Dueck AC, Mendoza TR, Mitchell SA, Reeve BB, Castro KM, Rogak L, et al. Validity and Reliability of the US National Cancer Institute's Patient-Reported Outcomes Version of the Common Terminology Criteria for Adverse Events (PRO-CTCAE). JAMA Oncol. 2015;1(8):1051-9. http://www.ncbi.nlm.nih.gov/ pubmed/26270597.

21. Basch E, Reeve BB, Mitchell SA, Clauser SB, Minasian LM, Dueck AC, et al. Development of the National Cancer Institute's patient-reported outcomes version of the common terminology criteria for adverse events (PRO-CTCA E). J Natl Cancer Inst. 2014;106(9). http://www.ncbi.nlm.nih.gov/pubmed/252 65940.

22. Hay JL, Atkinson TM, Reeve BB, Mitchell SA, Mendoza TR, Willis G, et al. Cognitive interviewing of the US National Cancer Institute's PatientReported Outcomes version of the Common Terminology Criteria for Adverse Events (PRO-CTCAE). Qual Life Res. 2014;23(1):257-69. http://www. ncbi.nlm.nih.gov/pubmed/23868457.

23. Knoerl R, Gray E, Stricker C, Mitchell SA, Kippe K, Smith G, et al. Electronic versus paper-pencil methods for assessing chemotherapy-induced peripheral neuropathy. Support Care Cancer. 2017;25(11):3437-46. http:// www.ncbi.nlm.nih.gov/pubmed/28577231.
24. McCrary JM, Goldstein D, Trinh T, Timmins HC, Li T, Friedlander M, et al. Optimising clinical screening for chemotherapy-induced peripheral neuropathy. J Pain Symptom Manag. 2019. https://linkinghub.elsevier.com/ retrieve/pii/S0885392419304348.

25. Tofthagen C. Patient perceptions associated with chemotherapy-induced peripheral neuropathy. Clin J Oncol Nurs. 2010;14(3):E22-8. http://www.ncbi. nlm.nih.gov/pubmed/20529785.

26. Postma TJ, Aaronson NK, Heimans JJ, Muller MJ, Hildebrand JG, Delattre JY, et al. The development of an EORTC quality of life questionnaire to assess chemotherapy-induced peripheral neuropathy: the QLQ-CIPN20. Eur J Cancer. 2005;41(8):1135-9.

27. Smith EML, Barton DL, Qin R, Steen PD, Aaronson NK, Loprinzi CL. Assessing patient-reported peripheral neuropathy: the reliability and validity of the European Organization for Research and Treatment of Cancer QLQ-CIPN20 questionnaire. Qual Life Res. 2013;22(10):2787-99.

28. Yeo F, Ng CC, Loh KWJ, Molassiotis A, Cheng HL, Au JSK, et al. Minimal clinically important difference of the EORTC QLQ-CIPN20 for worsening peripheral neuropathy in patients receiving neurotoxic chemotherapy. Support Care Cancer. 2019:1-10. http://link.springer.com/10.1007/s00520-01 9-04771-8.

29. Greenlee H, Hershman DL, Shi Z, Kwan ML, Ergas IJ, Roh JM, et al. BMI, Lifestyle Factors and Taxane-Induced Neuropathy in Breast Cancer Patients: The Pathways Study. J Natl Cancer Inst. 2017;109(2):djw206. https://aca demic.oup.com/jnci/article-lookup/doi/10.1093/jnci/djw206.

30. Petrovchich I, Kober KM, Wagner L, Paul SM, Abrams G, Chesney MA, et al. Deleterious Effects of Higher Body Mass Index on Subjective and Objective Measures of Chemotherapy-Induced Peripheral Neuropathy in Cancer Survivors. J Pain Symptom Manag. 2019;0(0). http://www.ncbi.n/m.nih.gov/ pubmed/31047960.

31. Hershman DL, Lacchetti C, Dworkin RH, Lavoie Smith EM, Bleeker J, Cavaletti $\mathrm{G}$, et al. Prevention and management of chemotherapy-induced peripheral neuropathy in survivors of adult cancers: American Society of Clinical Oncology clinical practice guideline. J Clin Oncol. 2014;32(18):1941-67.

32. Majithia N, Loprinzi CL, Smith TJ. New Practical Approaches to Chemotherapy-Induced Neuropathic Pain: Prevention, Assessment, and Treatment. Oncology (Williston Park). 2016;30(11):1020-9. http://www.ncbi. nlm.nih.gov/pubmed/27854104.

33. Knoerl R, Gilchrist L, Kanzawa-Lee GA, Donohoe C, Bridges C, Lavoie Smith EM. Proactive rehabilitation for chemotherapy-induced peripheral neuropathy. Semin Oncol Nurs. 2020;36:150983. http://www.ncbi.nlm.nih. gov/pubmed/31959510.

34. Knoerl R, Kanzawa G, Smith E. Chemotherapy-induced peripheral neuropathy: answering your questions about this common nerve condition caused by chemotherapy treatment. Coping Cancer. 2015; p. 10. https:// copingmag.com/chemotherapy-induced-peripheral-neuropathy/.

35. McCrary JM, Goldstein D, Boyle F, Cox K, Grimison P, Kiernan MC, Krishnan AV, Lewis CR, Webber K, Baron-Hay S, Horvath L, Park SB. In focus Delphi working party. Optimal clinical assessment strategies for chemotherapyinduced peripheral neuropathy (CIPN): a systematic review and Delphi survey. Support Care Cancer. 2017;25(11):3485-93. https://doi.org/10.1007/ s00520-017-3772-y. Epub 2017 Jun 7.

36. Kleckner IR, Kamen C, Gewandter JS, Mohile NA, Heckler CE, Culakova E, et al. Effects of exercise during chemotherapy on chemotherapyinduced peripheral neuropathy: a multicenter, randomized controlled trial. Support Care Cancer. 2017. http://www.ncbi.nlm.nih.gov/pubmed/2 9243164.

37. Zimmer P, Trebing S, Timmers-Trebing U, Schenk A, Paust R, Bloch W, et al. Eight-week, multimodal exercise counteracts a progress of chemotherapyinduced peripheral neuropathy and improves balance and strength in metastasized colorectal cancer patients: a randomized controlled trial. Support Care Cancer. 26(2).

38. Smith EM, Pang H, Cirrincione C, Fleishman S, Paskett ED, Ahles T, et al. Effect of duloxetine on pain, function, and quality of life among patients with chemotherapy-induced painful peripheral neuropathy: a randomized clinical trial. JAMA. 2013;309(13):1359-67.

39. Colquhoun HL, Squires JE, Kolehmainen N, Fraser C, Grimshaw JM. Methods for designing interventions to change healthcare professionals' behaviour: a systematic review. Implement Sci. 2017;12(1):30. http://implementa tionscience.biomedcentral.com/articles/10.1186/s13012-017-0560-5.

40. Powell BJ, Waltz TJ, Chinman MJ, Damschroder LJ, Smith JL, Matthieu MM, et al. A refined compilation of implementation strategies: results from the 
expert recommendations for implementing change (ERIC) project. Implement Sci. 2015 Feb;12:10(1).

41. Waltz TJ, Powell BJ, Matthieu MM, Damschroder L, Chinman MJ, Smith JL, Proctor EK, Kirchner JE. Use of concept mapping to characterize

relationships among implementation strategies and assess their feasibility and importance: results from the Expert Recommendations for Implementing Change (ERIC) study. Implement Sci. 2015;10:109. https://doi. org/10.1186/s13012-015-0295-0.

42. Aarons GA, Hurlburt M, Horwitz SM. Advancing a Conceptual Model of Evidence-Based Practice Implementation in Public Service Sectors. Adm Policy Ment Health Ment Health Serv Res. 2011;38(1):4-23. http://link. springer.com/10.1007/s10488-010-0327-7.

43. Mitchell SA, Chambers DA. Leveraging implementation science to improve Cancer Care delivery and Patient outcomes. J Oncol Pract. 2017 Aug;13(8): 523-9.

44. Salgado TM, Quinn CS, Krumbach EK, Wenceslao I, Gonzalez M, Reed HL, Syverson JG, Etz RS, Vangipuram K, Barker MR, Henry NL, Farris KB, Hertz DL. Reporting of paclitaxel-induced peripheral neuropathy symptoms to clinicians among women with breast cancer: a qualitative study. Support Care Cancer. 2020;28(9):4163-72. https://doi.org/10.1007/s00520-019-052546. Epub 2020 Jan 2.

\section{Publisher's Note}

Springer Nature remains neutral with regard to jurisdictional claims in published maps and institutional affiliations.

Ready to submit your research? Choose BMC and benefit from:

- fast, convenient online submission

- thorough peer review by experienced researchers in your field

- rapid publication on acceptance

- support for research data, including large and complex data types

- gold Open Access which fosters wider collaboration and increased citations

- maximum visibility for your research: over $100 \mathrm{M}$ website views per year

At $\mathrm{BMC}$, research is always in progress.

Learn more biomedcentral.com/submissions 